\title{
Ergonomics and workplace design: application of Ergo-UAS System in Fiat Group Automobiles
}

\author{
Vitello M. ${ }^{\mathrm{a}^{*}}$, Galante L.G. ${ }^{\mathrm{a}}$, Capoccia M. ${ }^{\mathrm{a}}$, Caragnano G. ${ }^{\mathrm{b}}$ \\ a. Fiat Group Automobiles, Manufacturing Planning \& Control, Turin, Italy \\ b. PricewaterhouseCoopers Advisory Spa, Operation, Milan, Italy
}

\begin{abstract}
Since 2008 Fiat Group Automobiles has introduced Ergo-UAS system for the balancing of production lines and to detect ergonomic issues. Ergo-UAS system integrates 2 specific methods: MTM-UAS for time measurement and EAWS as ergonomic method to evaluate biomechanical effort for each workstation. Fiat is using a software system to manage time evaluation and ergo characterization of production cycle (UAS) to perform line balancing and obtain allowance factor in all Italian car manufacturing plant. For new car models, starting from New Panda, FGA is applying Ergo-UAS for workplace design since the earliest phase of product development. This means that workplace design is based on information about new product, new layout, new work organization and is performed by a multidisciplinary team (Work Place Integration Team), focusing on several aspects of product and process: safety, quality and productivity. This allows to find and solve ergonomic threats before the start of production, by means of a strict cooperation between product development, engineering and design, manufacturing. Three examples of workstation design are presented in which application of Ergo-UAS was determinant to find out initial excessive levels of biomechanical load and helped the process designer to improve the workstations and define limits of acceptability. Technical activities (on product or on process), or organizational changes, that have been implemented in order to solve the problems are presented. A comparison between "before" and "new" ergonomic scores necessary to bring workstations in acceptable conditions were made.
\end{abstract}

Keywords: Ergo-UAS, EAWS, MTM, Workplace design, automotive, production line.

\section{Ergo-UAS industrialization: management of a massive amount of data to integrate ergonomics into product design and production processes}

Since 2007 Fiat Group Automobiles adopted UAS method to assign a basic time to execute a motion of an activity described on process sheets where production cycles are structured and measured with a standard and universal system (MTM-UAS, MethodsTime Measurement). Furthermore, FGA has introduced an ergonomic method, EAWS, to calculate, for each work-station, the proper biomechanical load. The previous system, to set standard time applied a relatively constant allowance to each single motion (about $4 \div 6 \%$ ), as a function of body postures and forces.

Ergo-UAS system connects UAS with EAWS because to feed EAWS method is necessary to input a lot of ergonomic parameters (postures, forces, actions and grip, material manual handling, trolley pushing and pulling) directly on each row of UAS analysis. By the overall working tasks assignment to a workstation (line balancing), Ergo-UAS aims at controlling and limiting the work-load within the compliance ranges set by ISO/CEN standard. Ergo-UAS determines an ergonomic allowance factor, which, added to the total basic time (UAS time) gives the so called standard time. The Ergo-UAS model ranges

\footnotetext{
*Corresponding author: E-mail:marco.vitello@fiat.com. Phone:+ 390110035175
} 
from a minimum allowance of $1 \%$ to a maximum theoretical value of $52 \%$. For workstation under control and well-designed the maximum allowance value is $13,5 \%$.

The core challenges during Ergo-UAS implementation and management are:

- Magnitude of data: UAS analysis, ergo characterizations, Fiat data-blocks, product validities, work cycles, production program (mix of production)

- Speed and frequency of change (business dynamic condition)

\section{Proposal method to perform Ergo-UAS system in Fiat Group Automobiles and data management}

Fiat Group Automobiles introduced Ergo-UAS system in all Italian plants: firstly Mirafiori (Turin) in 2007.

Several introductive and propaedeutic activities have been executed to start Ergo-UAS application:

- to adopt only one software to build the database, where time evaluation (UAS) and ergonomic data of production cycles, line balancing and related EAWS scores (for each business unit of each plant and for each car model) are managed togheter.

- to create an important database of about one thousand of UAS standard data-blocks (Fiat data-block) to standardize an reduce arbitrariness of applicator, divided for business unit (press shop, body shop, paint shop, assembly shop), and for main categories of application: electrical and hydraulic connections, cleaning, aids handling, manual fastening, fastening with guns, riveting, body movements, plugs or plastic components application, harness, sealing, welding pliers etc.

- to create a set of ergonomic functionalities and utilities to make easier, standard and intuitive ergonomic data to characterize analysis. For instance, geometries and external and interior dimensions of car and layout ware mapped to determine working conditions and expected zone/posture. Moreover, a massive analysis of weight, grip, activation force, hand used of a large amount of tools, aids, parts was performed to define a large set of ergonomic information to be used during analysis characterization.
- to define common rules and working approaches (procedures) with all functions involved in this activities

Currently, Fiat Group Automobiles has applied ErgoUAS in 5 plants for up to 10 car models, using common and standard application and approach to manage UAS and ergonomic analysis of all product cycles. Currently, more than 100 thousand of time elements with ergonomic characterization populate a shared database and about 2 thousands are the balancing yearly produced by the plants.

The FGA Ergo-UAS system is always up to date with a product/process/volume/mix changes ensuing a constant control on productivity and ergonomics. In fact, by an update of cycle analysis and production program (mix of production), system quickly generates a new calculation of working load of each workstation and related EAWS score and allowances factor.

\section{Ergo-UAS application vs. traditional system. FGA cases study: Ergo-UAS application approach in 3 workstations submit to ergonomic risks}

In Figure 1 the single motion fatigue allowance distribution in a trim line balancing is presented. In this case, fatigue allowances have an average value (4-6 $\%$ ) of basic time and they have approximately the same value in each work-station (see dark blue graph in Figure 1)

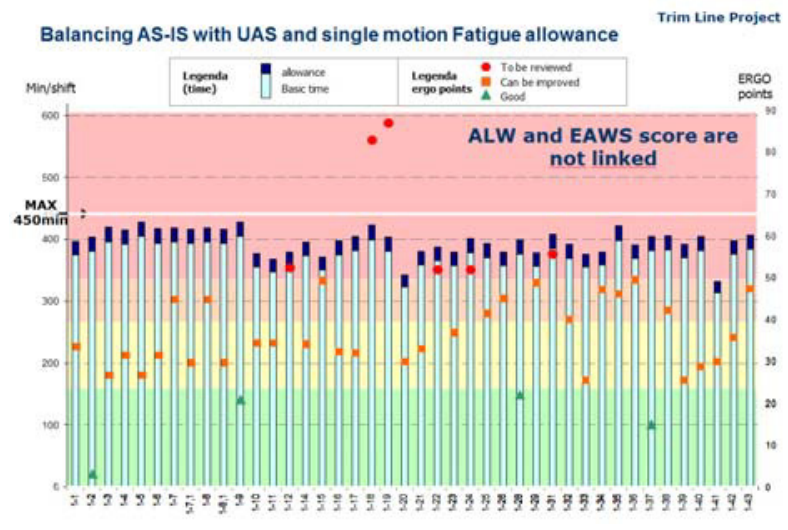

Fig. 1 - Single motion fatigue allowance distribution in a trim line balancing 


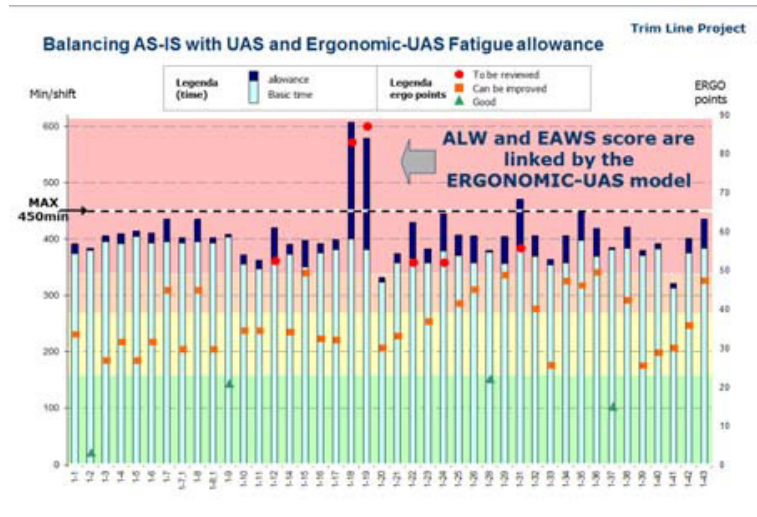

Fig. 2 - Balancing as-is with Ergo-UAS fatigue allowances

In Figure 2, the previous balancing is replaced as-is using Ergo-UAS method. In this case, allowance factor changes for each workstation according with biomechanical load. Ergo-UAS application determines that balancing as-is is not acceptable because some workstations present standard time (basic time + allowance factor time) greater than maximum balancing time (450 minutes/shift).

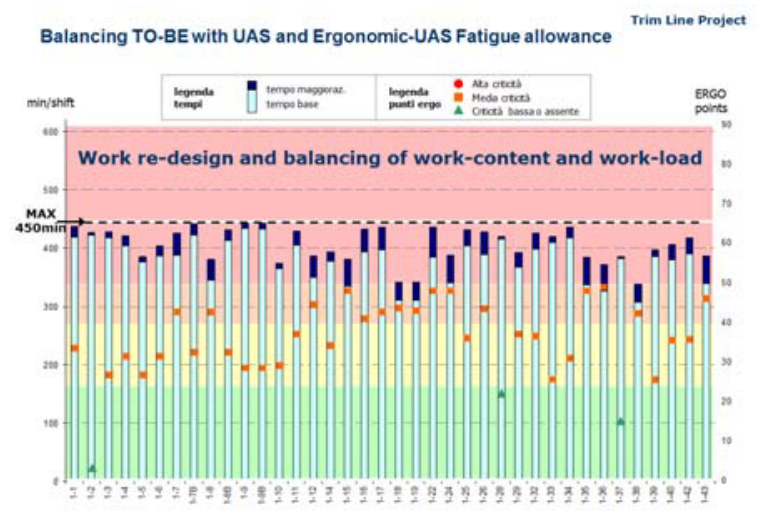

Fig. 3 - Balancing to-be with Ergo-UAS fatigue allowances

In Figure 3, a new trim line balancing is presented. With an optimization of tasks assignment, it's possible to better assign and share activities to all workstations, improving general ergonomic effort and increasing productivity.
For new car models, starting from New Panda, Fiat Group Automobiles is applying Ergo UAS for workplace design during product development phase. This means that workplace design is based on information about new product, new layout, new work organization and is performed by a multidisciplinary team (Work Place Integration Team), focusing on several aspect of product and process: safety, quality, productivity, ergonomics, work analysis. This allowed to find and solve ergonomic threats before the start of production, by means of a strict cooperation between product development, engineering and design, manufacturing departments. In the case will be considered 3 examples of workstation design in which application of Ergo UAS was determinant to find out initial excessive levels of biomechanical efforts and helped the process designer to improve the workstations, enter limits of acceptability. We have reported technical activities (on product or on process), or organizational changes, that have been implemented in order to solve the problems, making a comparison between "before" and "new" ergonomic scores that bring workstations in acceptable conditions.

Paper's cases study cope with three real different situations, in which different ergonomic critically are outcrop.

They represent three Fiat workstations and can be identified as assembly phases of cars production. In detail:

1. Mirafiori plant, Alfa Romeo MiTo (line 5), U.T.E. 3, workstation "hatch back harness"

2. Melfi plant, Fiat Punto, U.T.E. 3 workstation "left safety belt"

3. GB Vico plant, Fiat New Panda, U.T.E. 1, workstation " 3 " stop"

\section{Case study $n^{\circ} 1$}

In this case study ergonomic problems was focused on bad postures time (upright, arms at / above shoulder level) to complete insertion of harness on hatch interior space. Moreover, harness assembly activity cannot be split because guarantee high level of quality and represent a big amount of working time, considering production level and resulting takt time for one worker. In this case, a managerial solution was adopted to solve these problems.

\section{Case study $n^{\circ} 2$}

Second case study concerns fastening of safety belt with guns. Utilization of traditional battery guns determined a big amount of reaction force on arms and 
shoulder to counterbalance torque wrench. EAWS section involved in this issue is section Force (item 18 , force on arms and shoulder). In figure 4, two picture with new WiFi gun and traditional gun
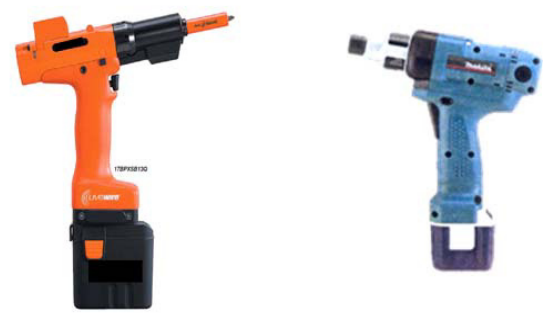

Fig. 4-New WiFi gun on the left, traditional gun on the right

\section{Case study $n^{\circ} 3$}

In this case study, problem was identified on third stop module's light insertion load (Newton needed to complete assembly).

\section{Solution of cases study, final consideration}

\section{Case study $n^{\circ} 1$}

Bad posture time for each cycle and work overload to perform completed harness assembly in this workstation was handled introducing a managerial solution. At the beginning, workstation activities was performed by 1 worker, with high percentage of saturation rate and dangerous time per cycle of critical posture. Workstation activities are now performed by two operators that work same activity: first of two workers on car A, second of two workers on car B. In this way, takt time for each worker became doubled because production level is divided by 2 for each worker. This solution produces a decrease of bad posture time per cycle and EAWS score goes from yellow section to green section. Moreover, saturation time is decreased and it admits a better physical rest on the inside of working shift. In Figure 6, a graphic view of adopted solution.

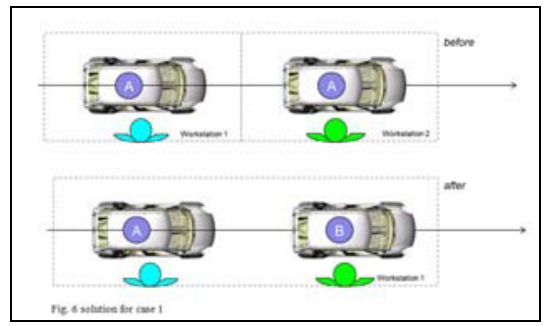

Fig. 5 - Solution for case 1

\section{Case study $n^{\circ} 2$}

Utilization of traditional battery guns determined a big amount of reaction force on arms and shoulder to counter-balance torque wrench. Gun length (from handgrip to screwing point) is increased to reduce reaction force, ac-cording with function

$$
F=\frac{C}{b}
$$

where:

$\mathrm{C}=$ fastening nominal torque wrench $(\mathrm{Nm})$

$\mathrm{b}=\operatorname{arm}$ of lever $(\mathrm{m})$

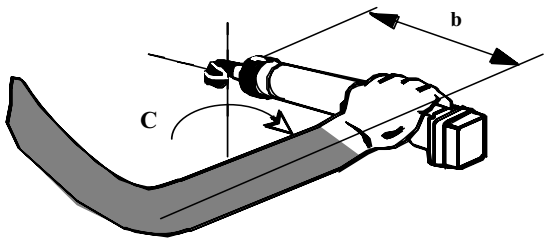

Fig. 6

Before $\mathrm{F}=15 \mathrm{Nm} / 0.28 \mathrm{~m}=53 \mathrm{~N}$

After $F=15 \mathrm{Nm} / 0.36 \mathrm{~m}=41 \mathrm{~N}$

In this case, a process solution was adopted to solve this ergonomic point.

\section{Case study $n^{\circ} 3$}

A shared solution in product design phase was implemented with cooperation between manufacturing dept., Engineering \& Design dept., $3^{\circ}$ stop module supplier, basing on a benchmark analysis of competitor solutions

For older model, insertion load was $202 \mathrm{~N}$ (with two hands), after technical action on module's springs hardness, this value was reduced to $155 \mathrm{~N}$. After further investigations with module supplier, it was possible to get final insertion value of $94 \mathrm{~N}$. In Figure 8, a picture of internal testing of supplier material with dynamometer. 


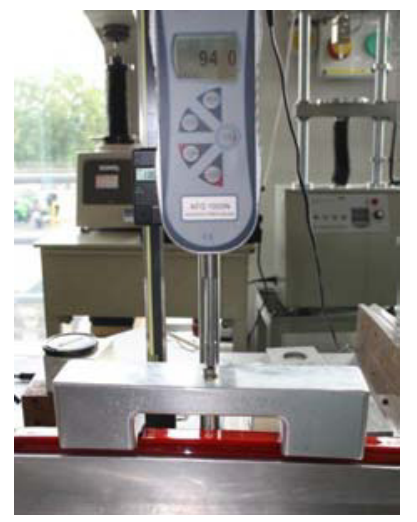

Fig. 7 - A phase of material testing

\section{References}

[1] Schaub K.H., Caragnano G, Britzke B, Bruder R., The European Assembly Worksheet, proceedings of the Conference ORP 2010 in Valencia, Institute of Ergonomics, International MTM Directorate, MTM-Institute / Deutsche MTM, Institute of Ergonomics / Darmstadt University of Technology
[2] Colombini, D; Occhipinti, E; and Grieco, A.: Risk Assessment and Management of Repetitive Movements and Exertions of Upper Limbs. Elesevier Ergonomics Book Series Volume 2. Amsterdam Elsevier 2002.

[3] Council Directive 90/269/EEC of 29 May 1990 on the minimum health and safety requirements for the manual handling of loads where there is a risk particularly of back injury to workers (fourth individual Directive within the meaning of Article 16 (1) of Directive 89/391/EEC) (Official Journal L 156 , 21/06/1990 P. 0009 - 0013)

[4] DIRECTIVE 2006/42/EC OF THE EUROPEAN PARLIAMENT AND OF THE COUNCIL of 17 May 2006 on machinery, and amending Directive 95/16/EC (recast). (Official Journal of the European Union L 157/24. 9.6.2006) [5] ISO 12100-1:2003. Safety of machinery - Basic concepts, general principles for design - Part 1: Basic terminology, methodology

[6] ISO 12100-2:2003. Safety of machinery - Basic concepts, general principles for design - Part 2: Technical principles [7] ISO 14121-1:2007. Safety of machinery — Risk assessment Part 1: Principles

[8] ISO 14121-2:2007. Safety of machinery - Risk assessment Part 2: Practical guidance and examples of methods [9] EN 614-1:2006/prA1:2008. Safety of machinery - Ergonomic design principles - Part 1: Terminology and general principles. [10] EN 1005-2:2003+A1:2008. Safety of machinery - Human physical performance - Part 2: Manual handling of machinery and component parts of machinery

[11] EN 1005-3:2002+A1:2008. Safety of machinery - Human physical performance - Part 3: Recommended force limits for machinery operation. 